\title{
Study on the Qiang's Costume Culture-A Case Study of the Qiang's Costumes in Li County
}

\author{
Chunlei Song, Bing Zhao* \\ Southwest University for Nationalities, Chengdu, China \\ Email: 790264116@qq.com, *zhaobin_swun@sina.com
}

How to cite this paper: Song, C.L. and Zhao, B. (2018) Study on the Qiang's Costume Culture-A Case Study of the Qiang's Costumes in Li County. Open Journal of Social Sciences, 6, 225-234. https://doi.org/10.4236/jss.2018.66020

Received: June 1, 2018

Accepted: June 26, 2018

Published: June 29, 2018

Copyright ( $\odot 2018$ by authors and Scientific Research Publishing Inc. This work is licensed under the Creative Commons Attribution International License (CC BY 4.0).

http://creativecommons.org/licenses/by/4.0/

\section{(c) (i) Open Access}

\begin{abstract}
As a part of fifty-six ethnic minorities, the Qiang ethnic has long-established national culture and is also an important part of intangible cultural heritage. The article outlines the connotation of the Qiang's culture, elaborates the aesthetic characteristics, pattern characteristics, color characteristics, and compositional characteristics of the Qiang's costumes. Taking the Qiang's costumes in the Mao County area as an example, through analysing the materials of Qiang's costumes in the Mao County, the paper deeply analyzes the differences in cultural customs and dressing habits between different regions. The unique geographical features of Li County's clothing are summarized based on these differences. The Qiang ethnic calls itself "er ma" or "er mie", and it is also being called "nation on the cloud". They are mainly distributed in Maoxian, Wenchuan, Lixian, Songpan and Heishui counties in Aba Tibetan and Qiang Autonomous Prefecture of Sichuan Province and Beichuan Qiang Autonomous County in Mianyang City. The rest are scattered in Danba County in Ganzi Tibetan Autonomous Prefecture of Sichuan Province, Pingwu County in Mianyang City and Jiangkou County and Shiji County in Tongren Prefecture of Guizhou Province. This article focuses on Qiang costume culture in Li County of Aba Tibetan and Qiang Autonomous Prefecture in Sichuan Province.
\end{abstract}

\section{Keywords}

Qiang Ethnic, Qiang's Costume, Ethnic Culture

\section{Cultural Connotation of Qiang's Costumes}

\subsection{Worship of Sheep}

Ancient Qiang people use sheep as a totem and have the custom of worshipping sheep. Sheep are the wealth and the essential trading and material economic 
sources in the lives of the Qiang people. Sinologists have verified that the word “羌” is actually a variant of the word “羊”. The Qiang ethnic and the sheep have a close relationship. Because the sheep are gentle, easy to be tamed, and the fur is the best clothing to resist the cold, so it has a lot of use value. Therefore, the Qiang people can not only obtain the necessities of life from the sheep but also use the sheep as a tribute to the ritual sacrifices, because the people of the Qiang ethnic believe that the sheep have a soul and can shelter and protect the safety of their tribal members. As a result, sheep worship and sheep totems have been created.

The Qiang people have a close connection with the sheep throughout their lives. The hat worn by the newborn child is decorated with wool, which means hoping to be sheltered and blessed by the sheep. When the child reaches the age about eleven, he will have an adult ceremony, then the Qiang's Shibi removes the wool from the hat and puts it on the neck of the blessing, and it is marked with a flower knot so that the sheep can protect their life. After the old man passed away, a sheep would be killed as its guide, and people sprinkle the blood of the sheep in the hands of the deceased, which means that the deceased "drive the sheep to the west" [1]. In daily life, the Qiang people like to wear sheepskin pimple (Figure 1). They use wool spinning to make clothes. And the pattern on the clothes is also inseparable from the sheep's pattern. The most representative pattern is the "four corners guard flowers" (Figure 2) and "Crocus flower".

\subsection{Worship of White Stone}

The Qiang people worship white stone, and everywhere in the Qiang Village, you can see the white stone on the roof of every household, which represents the five gods that the Qiang people most admire-God, Divine God, Mountain God, Tree God, and Home God. The Qiang people's worship of the White Stone has many legends in the folk. Among them, the most widely spread is the "Qiang Ge Wars". It says that the ancestors of the Qiang ethnic met the vicious Gogi in the process of migrating to the upper reaches of the Minjiang River, so they prayed for help to the gods, and received guidance from the gods from their dreams,

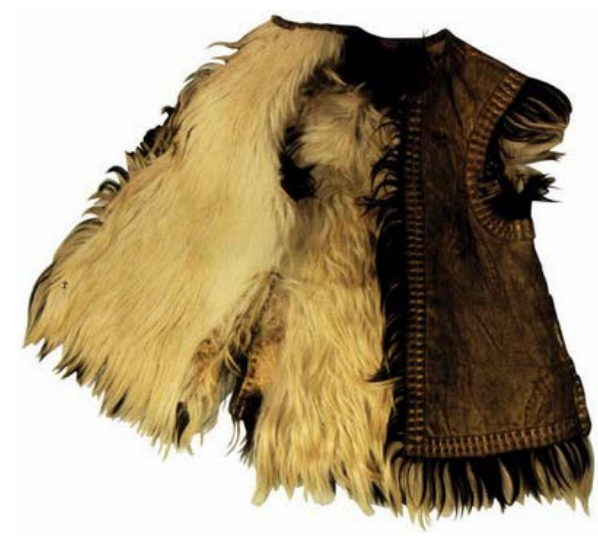

Figure 1. Sheepskin pimple. 


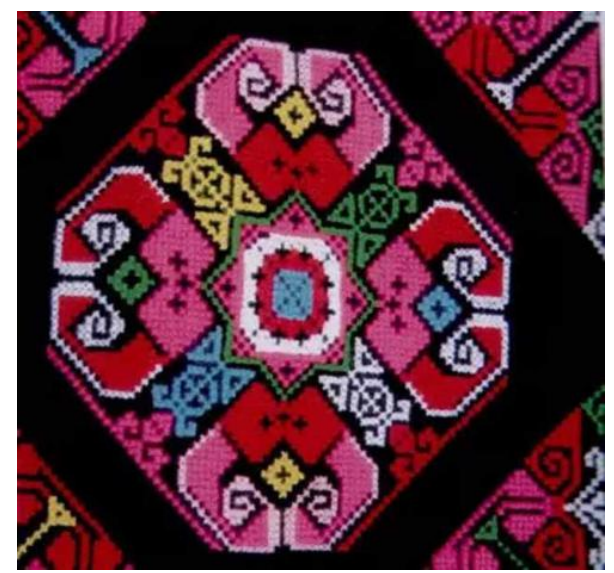

Figure 2. Four corners guard flowers.

and finally defeated the Gogi people with White Stone as weapons. In order to repay the blessing of the God, the white stone was enshrined for generations and white stone was the god of heaven.

The Qiang people's worship for white is derived from the worship of White Stone. They use White Stone as auspiciousness and a symbol of truth, goodness, and beauty. At the same time, the Qiang people have long used the love of white in the clothing, such as white headdresses, white gowns and waistcoats.

\subsection{Worship of Fire}

The Qiang people advocate the fire mainly in two forms of fire cremation and fire sacrifice. First of all, cremation is the development and continuation of the Qiang people's awe and advocacy of fire; the advocacy of fire is mainly manifested in the funeral of the Qiang people. It is believed that the fire has a purifying effect. After a person dies, it can introduce the soul into the kingdom of heaven and meet his loved ones. Followed by the fire sacrifice, there will be fire pits in the Qiang people's households and be regarded as the holiest and most important place in the family. Fire in the fire pits continues, known as the "The gold furnace continues for thousands of years of fire". It symbolizes that the people of the Qiang ethnic are booming and prosperous. During the festival, the people of the Qiang ethnic will also dance around the flame pool names "Shalang".

Qiang people's worship of fire is also reflected in dress and embroidery. For example, a man's belt is bound to hang a small fire, it is a very important ornament. Another example is the Yunyun shoes that are decorated by the fire enamel pattern. (Figure 3) At the toe, the fire enamel pattern will turn into a moire pattern. At the same time, these fire enamel patterns will also appear on the Qiang people's waistcoats and gowns.

\subsection{Worship of the Sun}

The Qiang people's worship of the sun is also very prominent. The Qiang people respect the sun as one of the twelve gods, and regard the sun god as the head of 


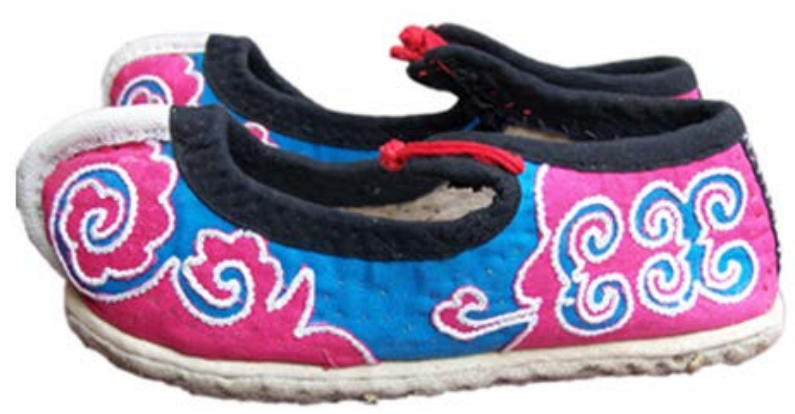

Figure 3. Fire enamel pattern on Qiang “yunyun” shoes.

the gods and believe that the sun god and the gods are the greatest. The Qiang people see the sun as important as the fire. The proverb states the sun as "mu se shi guo", and translates to "bake the heat". The sun and the fire are considered as one. During the festivals, in order to thank the sun for the light and warmth it brings to the earth, the Qiang people will present "Sun Bagua" and sing the song "Shout the Sun".

Sun patterns are also often used as patterns in Qiang costumes and buildings. For example, the flower band worn on the Qiang people is an important accessory that both men and women must affix to the waist. The pattern above is the symbol of sun, "Wanzi pattern". This pattern gives the flower band magical magic and is believed to be able to exorcise evil spirits. Therefore, when the Qiang girls were married, wearing a "Wanzi pattern" flower belt implies holy and untainted. In the Qiang people's buildings, we often see patterns such as Wanzi pattern, cross patterns, and solar patterns that not only express the worship of the Sun by the Qiang people, but also decorate and beautify the walls.

\section{Aesthetic Characteristics of Qiang People's Costume Culture}

\subsection{Headband}

Both the men and the women of the Qiang people have the custom of keeping long hair and wearing scarf. Qiang women comb their long hair when they are teenagers, and pull them after marriage. The Qiang men shave their heads when they are seven years old. They only have a little hair at the front of the forehead, and then braid hair with blue lines together and braid them around the head. Qiang men usually pack black or white head coverings. The young men will lower their head and shoulders in front of their heads, thus demonstrating their imposing appearance. The women's headscarf is black and white. Unlike men, most women's headscarfs are embroidered and the style is divided into two types: baopa and dapa. The different styles of wearing headscarf in each region will show many different shapes. For example, women in Yonghe Town of Maoxian County will be coiled into discs; women in Songpinggou will be wrapped into big towering shape; women in Black Tiger Village will use two long white scarfs shape a mighty "General Pa" to commemorate the general sa- 
crificed for people to express people's respect for him and so on. The differences types in wearing headscarf fully reflect the mutual influence and mutual blending between different regions.

\subsection{Upper Clothing and Lower Clothing}

The clothing of the Qiang men and women has been preserved by the ancient Qiang people during the nomadic period, and they are still mainly gowns or robes. The length of a man's gown or robe is generally not more than knee length, and the color is mainly white, loose and hypertrophy, and the right collar is standing. Because the gown and robe are long and large, and there are no buttons, they are tied tightly by a belt. For convenience, they will pull the clothing shirt and robe up about 10 centimeters to cover the waistband. In addition, auspicious patterns such as a cross pattern and a tangram are embroidered on both the cuffs and the hem to pray for blessing and peace. Underwear is mainly based on dark trousers. Women's clothing is mainly red, dark blue and white, front and rear hem and hem will be decorated with moire, horn pattern. Underwear will be dominated by black loose trousers, legs will be legged with cotton or linen.

A sheepskin placket is worn on both the men's and women's gowns. It is one of the most representative clothing of the Qiang ethnic, especially when large-scale events are held, such as Sacrifice and the Qiang year. Sheepskin crickets are usually made of light-skinned sheepskin. There are no collars and cuffs, and long wool is exposed around them. Sheepskin crickets are flexible in use. When the weather is cold, they can maintain warmth, keep warm, and prevent rain. They can be used for weight-bearing and back mat to prevent abrasion.

\subsection{Shoe Clothing}

\section{1) Leggings}

As the Qiang people live in high-cold areas, leggings can not only resist cold but also prevent mosquitoes from biting. At the same time, they also have decorative effects. The color matching, embroidered decoration and binding methods of the leggings are very particular. There are still many in various regions [2]. For example, the method of red leggings is to tie the white linen on the ankle to the calf, put on the red leggings on it, and then fix it with a blue foot strap. The whole legging is composed of three colors: white, red and blue. The color is distinctive.

\section{2) Yunyun shoes}

The Qiang men's shoes are generally called “yunyun shoes”. Women's shoes are "pointed shoes" and "embroidered shoes". They are all made of fabrics. They are shaped like boats, the tips of the shoes are slightly curled and the soles are thick [3]. "Yunyun shoes" is the most representative; the upper is dominated by cloud patterns and sheep's head patterns. Sometimes the two are deformed to 
form different patterns to decorate. They contain profound meanings, and the colors are often black and blue, hell often shows a colorful pattern, elegant and colorful, both generous and beautiful. The pattern of "pointed shoes" is mainly plant-based, and there are some simple geometric patterns, meaning relatively simple.

\section{3) Accessories}

The Qiang' men and women's accessories are very rich, including aprons, streamers, wraps, and fire knives, knives, sachets, and silver ornaments worn on the belts. Waist ornaments are generally in the body of the Qiang women's chest and abdomen, waist and hips and other important parts of the body, fully bring out the Qiang women's curves and strong beauty. In the bosom, Qiang women will use beautiful patterns and bright colors and exquisite embroidery techniques to match the gown.

Men's aprons are mainly embroidered semi-circle aprons with black plains. Sometimes embroider some embroidered on the two pockets of the abdomen. The biggest difference from the woman's apron is that it will open five-centimeter slit in the middle of the hem, and embroider a small square embroidered pattern on top.

In addition to the bosom, in daily life, Qiang women will wear a variety of silver ornaments to dress themselves up, such as silver bracelets, silver earrings, silver hairpins, and some will use silver chains to connect silver rings and silver bracelets, and then hang small bell, making it look different. Qiang men will be decorated with silver ornaments, agate and turquoise fire bowls on their belts.

\section{Qiang Ethnic Clothing Types in Li County}

Li County is located in the south of the Aba Tibetan and Qiang Autonomous Prefecture in Sichuan Province. Zagunao River, which is a tributary of the Minjiang River, flows from the northwest to the southeast and runs through the entire territory. Li County's clothing is the crystallization of multi-cultural precipitation and integration in the long-term development process, thus forming a national costume culture with strong regional characteristics. The Qiang population in Li County is mainly concentrated in Xuecheng Town, Puxi Town, Muka Town, Tonghua Town and Taoping Town. Because here is a place where Han, Tibetan, and Qiang are interlaced, the clothing in the area is affected by the Han and the Tibetans. Representative Qiang costume areas are Puxi Town costumes, Taoping Town costumes and Muka Town costumes. Because Taoping Town and Muka Town are close to highways, the traffic is relatively convenient, and due to the government's various measures for the development of tourism in recent years, Qiang ethnic clothing in Taoping Town and Muka Town has gradually become commercialized and Market-oriented due to the development of tourism. Secondly, west of Muka Town is Jiarong Tibetan-inhabited area, and Taoping Town is near Wenchuan, making the Dong ethnicity of Muka Town and Taoping Town slightly different. The three regions are all within the jurisdiction 
of Li County. Their constituent elements and wearing methods are basically the same. However, due to geographical differences, traditional costumes in the three regions also show distinct personality characteristics. Therefore, choosing these three regions for comparison can give a more comprehensive picture of the differences in the clothing culture of the Qiang ethnic in the Li County affected by the geographical location. From the point of view of development, people in Li County have a weak awareness of the protection of Qiang ethnic's costume culture. Through the interpretation of the cultural connotation of Li County's costume, it is helpful to enhance modern people's awareness and protection awareness of Qiang costume.

\subsection{Taoping Town Clothing}

Taoping Town is located in the lower reaches of the Zagunao River, and is renowned for its magnificent mausoleums. It is known as the "Eastern Fort" and is famous around the world. Due to the development of tourism and government measures in recent years, the living standards of the local residents have been greatly improved. A complete commercial system has been formed in the Qiang Village, and the products on the pedestrian street are dazzling. The Qiang costumes everywhere are rich in color and beautiful in style.

\section{1) Men's clothing}

In a private museum in Taoping Town, the men's clothing of the early Qing Dynasty and the Republic of China was displayed. The main material is linen and the main color is white. Lace is placed in the neckline and damask, and there is a black or red belt around the waist, wearing a suede wrapped belly or embroidered cloth wrapped belly, wrapped belly can put some of the life of supplies, such as fire scorpion and tobacco and so on (Figure 4).

\section{2) Women's clothing}

Middle-aged women will pull their hair behind their heads and put on silver slivers and silver flowers, and finally wrap black silk. Wearing a blue gown, laces will be embroidered on the collar, placket and hem. The waist will be woven with a flower belt and a black embroidered vest. Finally, the apron with white flowers will be draped around. Silver jewellery is usually worn when the costume is worn (Figure 5).

\subsection{Puxi Town Clothing}

Puxi Town is located in the eastern part of Li County. The terrain is dominated by high mountain valleys and on both sides of Puxigou. The Qiang men's clothing here is free and easy, the women's clothing is exquisite, and the silver ornaments are gorgeous and colorful.

\section{1) Men's clothing}

The man's head has black and white headbands. The first is wrapped in a white bald head and then wrapped in a black headband. This makes the black head balm look slightly different. Usually people call this bald head bald a 


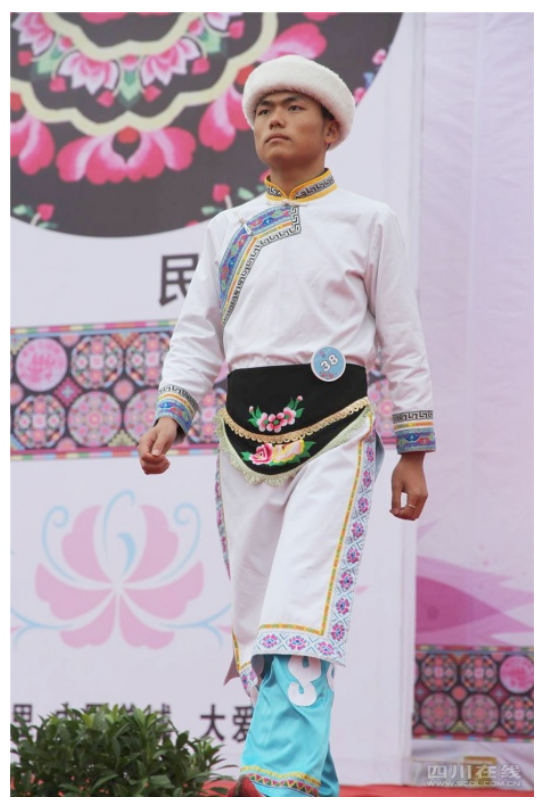

Figure 4. Taoping men's clothing.

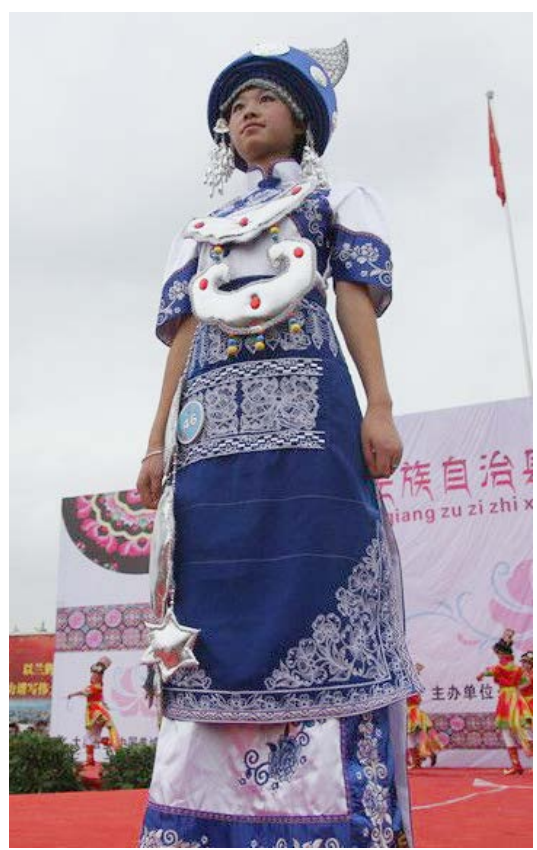

Figure 5. Taoping women's clothing.

"magpie head balm". Wearing a white linen gown and black vest, and wearing a white belt on the waist, underwearing black pants, black leggings, and then tied to the calf with a white foot strap. The body is dominated by black and white, with strong contrast (Figure 6).

\section{2) Women's clothing}

Having two scorpions when young and pulling their hair up when middle-aged. The form of wearing headscarf in Puxi Town is very different from that of the other two regions. The specific approach is to embroider a circle 


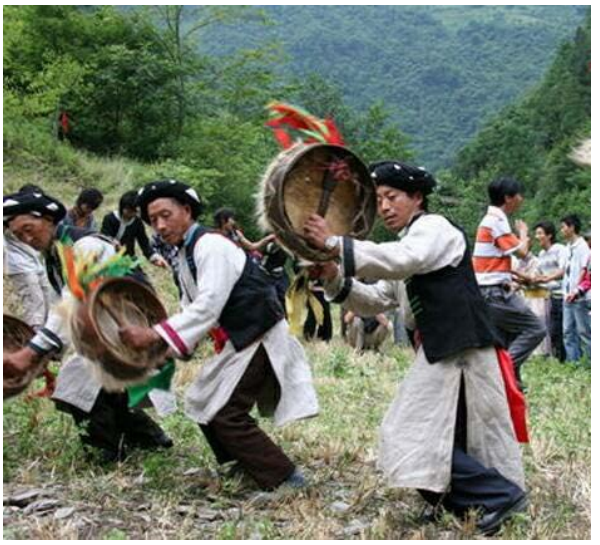

Figure 6. Puxi Men’s clothing.

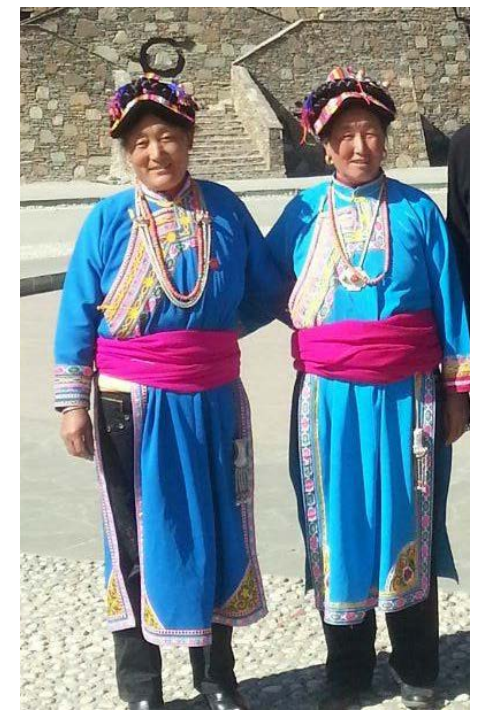

Figure 7. Puxi women's clothing.

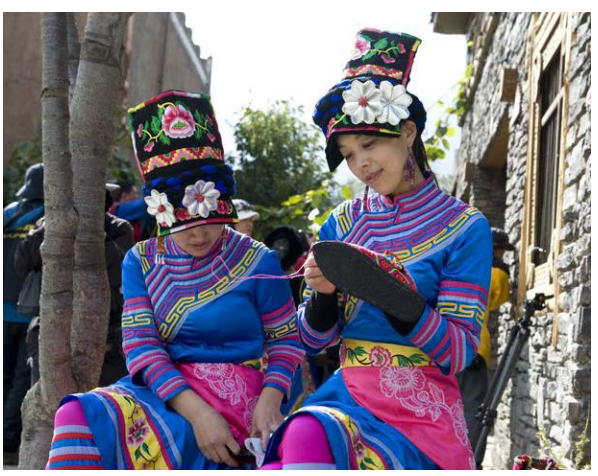

Figure 8. Muka women's clothing.

pattern on both ends of the head bald, and leave both ends outside so that the top two are on the top of the head. On the side, it feels like the top of the head has two flowers, often referred to as "croissant". Wearing a blue gown, lace, cuffs, hem, and both sides will be embroidered with lace, its pattern is generally 
moire, flame and sheep horn pattern, the waist is tied with picking apron, and finally tied in red and other colors belt (Figure 7).

\subsection{Muka Town Clothing}

Muka Town is located in the southeast corner of Li County. Its most special is the wrapping type of the head bald, in the form of "a piece of tile". The main method of wrapping is to fold a piece of cloth into a rectangular shape on top of the head, and then use tweezers to wrap it from the top of the head to the back of the head and fix it (Figure 8). The elderly will use a pure white and solid cloth to stand on top of their heads. The primary purpose is to look natural and simple. Secondly, the old man who has lost both parents will use a white head cradle and have the meaning of paying homage to the ancestors. Embroidery on the apron is mainly in the upper part of the apron and the hem, leaving white in the middle, and there is no pocket on the apron.

\section{Summary}

This article understands that dress culture is one of the most representative elements in Qiang culture and is an important part of the traditional national culture in China through the investigation and research on the status quo of the dress culture development of the Qiang people in Li County of Sichuan province. In the course of history, Qiang costumes continue to evolve while retaining their own characteristics. An in-depth interpretation of the Qiang ethnic's costume cultural characteristics can be seen in the course of its constant change in development. And it can also help us better understand the richness and diversity of traditional Chinese national culture. In the inheritance of traditional costume culture, more young people are encouraged to participate in the inheritance, so that the Qiang culture can be better developed and inherited.

\section{Acknowledgements}

This research was financially supported by Key Project of Southwest University for Nationalities 2018 Post graduate Student Innovative Research Projects (CX2018SZ148).

\section{References}

[1] Wang, M.K. (2008) Qiang is between the Han and the Tibetan: An Anthropological Study of the Dais in Western Sichuan. Zhonghua Book Company, Beijing.

[2] Zhang, Y. (2013) Study of Qiang ethnic's Creation Art. Tsinghua University Press, Beijing.

[3] Shen, L. and Xu, J. (2011) Analysis of Qiang Ethnic Embroidery Pattern Theme and National Cultural Connotation. Art Hundred. 